Check for updates

Cite this: RSC Adv., 2018, 8, 41692

Received 8th October 2018

Accepted 30th November 2018

DOI: $10.1039 / \mathrm{c} 8 \mathrm{ra0} 0334 \mathrm{~g}$

rsc.li/rsc-advances

\title{
A new family of fullerene derivatives: fullerene- curcumin conjugates for biological and photovoltaic applications $\uparrow$
}

Edison Castro, (D) *a Maira R. Cerón, (D) ab Andrea Hernandez Garcia, ${ }^{a}$ Quentin Kim, ${ }^{a}$ Alvaro Etcheverry-Berríos, (iD c Mauricio J. Morel, (D) ${ }^{c}$ Raúl Díaz-Torres, ${ }^{d}$ Wenjie Qian, ${ }^{d}$ Zachary Martinez, ${ }^{\mathrm{e}}$ Lois Mendez, ${ }^{a}$ Frank Perez, ${ }^{a}$ Christy A. Santoyo, ${ }^{a}$ Raquel GimenoMuñoz, ${ }^{d}$ Ronda Esper, ${ }^{a}$ Denisse A. Gutierrez, (D) e Armando Varela-Ramirez, (D) e Renato J. Aguilera, ${ }^{e}$ Manuel Llano, ${ }^{e}$ Monica Soler, (D) ${ }^{c}$ Núria Aliaga-Alcalde (D) df and Luis Echegoyen (D) *a

\begin{abstract}
The synthesis and characterization of a family of [60]fullerocurcuminoids obtained via Bingel reactions is reported. The new $\mathrm{C}_{60}$ derivatives include curcumin and curcuminoids with a variety of end groups. Preliminary biological experiments show the potential activity of the compound containing a curcumin addend, which exhibits moderate anti-HIV-1 and radical scavenger properties, but no anti-cancer activity. In addition, the new fullerocurcuminoids exhibit HOMO/LUMO energy levels that are reasonably matched with those of perovskites and when they were tested in perovskite solar cells (PSCs) as the electron transporting material (ETM), photoconversion efficiencies ranging from 14.04-14.95\% were obtained, whereas a value of $16.23 \%$ was obtained for $[6,6]$-phenyl- $\mathrm{C}_{61}$-butyric acid methyl ester $\left(\mathrm{PC}_{61} \mathrm{BM}\right)$ based devices.
\end{abstract}

\section{Introduction}

Since the discovery of $\mathrm{C}_{60}$ in 1985 by Kroto et al. ${ }^{1}$ fullerenes have attracted considerable attention due to their potential applications in biology and materials science. ${ }^{2-4}$ In 1993, Wudl and co-workers reported that fullerenes can inhibit HIV-1 viral infectivity, and they proposed a fullerene-induced inhibition mechanism involving binding to the protease (PR) active site based on the effect of these compounds on the in vitro activity of HIV-1 protease combined with in silico predictions. ${ }^{5,6}$ However, this paradigm was recently challenged by some of us, who showed that fullerenes do not inhibit HIV-1 protease activity in

${ }^{a}$ Department of Chemistry, The University of Texas at El Paso, 500W University Ave, El Paso, TX 79968, United States. E-mail: eacastroportillo@utep.edu; echegoyen@utep. edu

${ }^{b}$ Physical and Life Sciences, Lawrence Livermore National Laboratory, 7000 East Ave, Livermore, CA 94550, USA

'Departamento de Ingeniería Química, Biotecnología y Materiales, Facultad de Ciencias Físicas y Matemáticas, Universidad de Chile, Beauchef 851, Santiago, Chile ${ }^{d}$ CSIC-ICMAB (Institut de Ciéncia dels Materials de Barcelona), Campus de la Universitat Autónoma de Barcelona, 08193 Bellaterra, Spain

${ }^{e}$ Department of Biological Sciences, Border Biomedical Research Center, The University of Texas at El Paso, 500 West University Avenue, El Paso, TX 79968, USA

${ }^{f}$ ICREA (Institució Catalana de Recerca i Estudis Avançats), Passeig Lluís Companys 23, 08010 Barcelona, Spain

$\uparrow$ Electronic supplementary information (ESI) available. See DOI: 10.1039/c8ra08334g in vitro assays at doses that potently block HIV-1 maturation and infection. These findings indicate an alternative mode of viral inhibition that is yet to be determined..$^{7,8}$

The potential use of fullerene $\mathrm{C}_{60}$ and its derivatives as strong antioxidants to reduce reactive oxygen species (ROS) has also been explored. ${ }^{\mathbf{9}-12}$ Hydroxyl radicals are the most harmful among all species within the ROS family, ${ }^{\mathbf{1 3}}$ and previous studies have shown that $\mathrm{C}_{60}$ and its derivatives effectively scavenge hydroxyl radicals via reactions with the double bonds. ${ }^{7-9,14-16}$

Curcumin (CCM) is a polyphenolic natural product found in the food coloring turmeric (curry powder), a member of the ginger family. ${ }^{17} \mathrm{CCM}$ possesses diverse biological properties, such as anti-tumor, ${ }^{18}$ anti-oxidant, ${ }^{19}$ anti-arthritic, ${ }^{20}$ antiamyloid, ${ }^{21}$ and anti-inflammatory, ${ }^{22,23}$ among others. ${ }^{24,25}$ These potential biomedical applications are hindered by its low bioavailability and poor water solubility, although it is readily soluble in ethanol, DMSO, and acetone. ${ }^{26}$ On the other hand, straightforward synthetic methods for low cost and high yield preparation of curcumin have been reported. ${ }^{27,28}$ These facts have motivated the design and synthesis of curcumin derivatives, called curcuminoids (CCMoids), with the goal of overcoming some of the drawbacks, and many structural variations have been reported. ${ }^{29}$

For many years researchers have been studying the interesting biological properties of both curcumin, fullerene $\mathrm{C}_{60}$ and their derivatives as individual entities. ${ }^{3,29}$ However, to our 

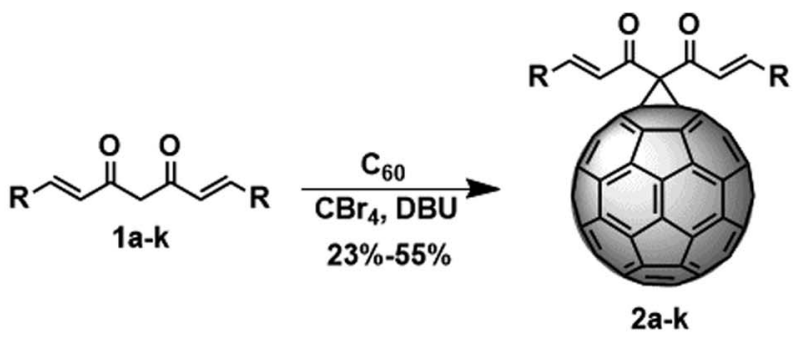

$\mathbf{R}$

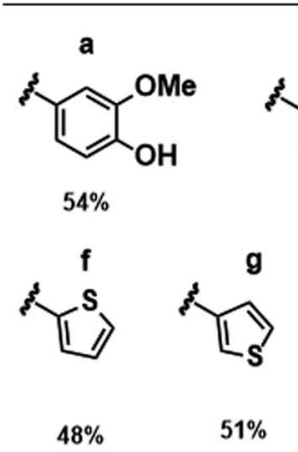

b

C<smiles>CCCCCOc1ccccc1</smiles>

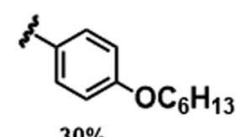<smiles>COc1ccc(C(C)(C)C)cc1</smiles>

$50 \%$

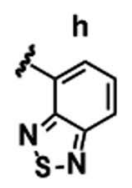

$29 \%$<smiles>c1cc2ccc3cccc4ccc(c1)c2c34</smiles>

$55 \%$<smiles>CC(C)(C)c1ccc2c(c1)Cc1ccccc1-2</smiles>

$31 \%$

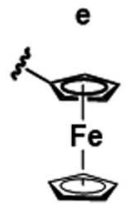
$52 \%$

Scheme 1 Synthesis of the fullerocurcuminoid derivatives $2 a-k$

knowledge, no one has covalently combined these two structures into conjugated derivatives. In this work, we present a straightforward approach to synthesize several fullerocurcuminoid $\mathrm{C}_{60}$ derivatives using the methylene between the two carbonyl groups to form a methanoadduct through an addition/elimination reaction (Bingel reaction). ${ }^{30}$ Preliminary biological and photophysical properties of these compounds were studied, testing the activity of $\mathrm{C}_{60}$-CCM against HIV, as a radical scavenger and for anticancer action. Some of the new compounds were also tested in inverted PSCs as ETMs. The main focus of this work is to provide a methodology for the synthesis of $\mathrm{C}_{60}$-CCMoids and to study some potential applications; thus detailed application studies are beyond the scope of this work.

\section{Results and discussion}

Synthesis of the fullerocurcuminoid $\mathrm{C}_{60}$ derivatives $2 \mathrm{a}-\mathrm{k}$

One of the most versatile reactions to functionalize fullerenes is the Bingel reaction, which involves an addition-elimination process to yield methanofullerenes. ${ }^{30}$ The target compounds 2a-k were synthesized using this reaction, where the Br-CCMoid anions were generated in situ using carbon tetrabromide $\left(\mathrm{CBr}_{4}\right)$ and 1,8-diazabicyclo[5.4.0]undec-7-ene (DBU) in ortho-dichlorobenzene (o-DCB) at room temperature. As represented in Scheme 1 eleven CCMoids 1a-k were reacted with $\mathrm{C}_{60}$ in the presence of $\mathrm{CBr}_{4}$ and $\mathrm{DBU}$ to yield the fullerocurcuminoid derivatives $2 \mathbf{a}-\mathbf{k}$ in $23-55 \%$ yields, using $3-30$ min reaction times (see the ESI $\uparrow$ for details). Longer reaction times led to the formation of bis- and poly-adduct products, which were not a)

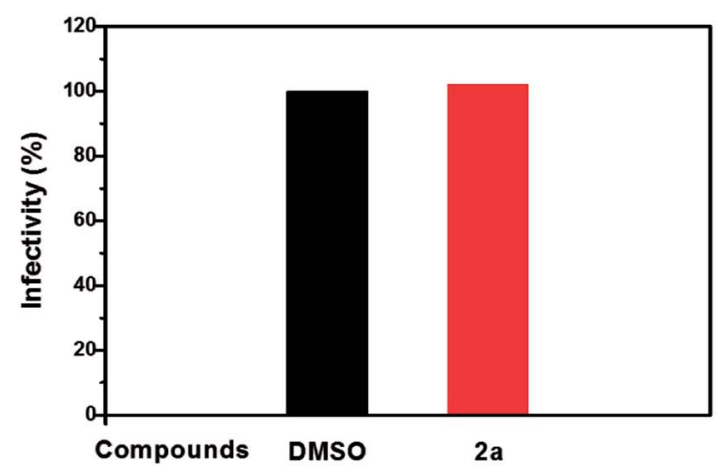

b)

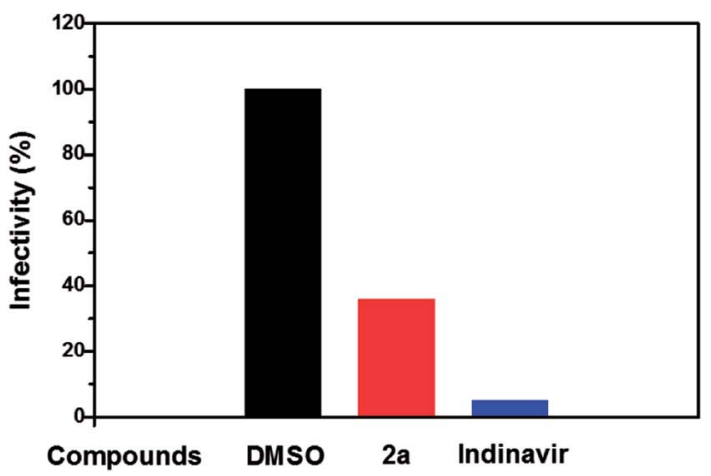

Fig. 1 Analysis of the viral life cycle step affected by compound 2a. (a) Effects on the early stages of the HIV-1 viral life cycle. (b) Effects of compound $2 a$ and indinavir on the late phase of the HIV-1 infection. VSV-G pseudotyped, single-round HIV-1 expressing luciferase were produced in the presence of DMSO, compound $2 \mathrm{a}(3 \mu \mathrm{M})$ and indinavir $(0.1 \mu \mathrm{M})$; the last one is a protease inhibitor used as a control. 
isolated. Among all the new derivatives $\mathbf{2 k}$ was the least soluble and the most unstable derivative; after one-week several dark spots were observed by thin layer chromatography (TLC). The chemical structures of compounds $\mathbf{1} \mathbf{b}-\mathbf{k}$ were confirmed by ${ }^{1} \mathrm{H}$ and ${ }^{13}$ C-NMR spectroscopy (Fig. S1-S10†) and 2a-k were characterized by matrix-assisted-laser-desorption-ionization-massspectrometry (MALDI-TOF-MS), ${ }^{1} \mathrm{H}^{-}$and ${ }^{13} \mathrm{C}-\mathrm{NMR}$ spectroscopy and UV-vis absorption (see ESI, Fig. S11-S32†).

The synthesized fullerocurcuminoids exhibited poor solubility in polar solvents such as DMSO or water, except for compound $\mathbf{2 a}$, due to the high solubility of the pristine CCM addend in DMSO. This low solubility in polar solvents and/or aggregation phenomena limited the biological studies exclusively to compound 2a. Compound 2 a was tested as an anti-HIV1 inhibitor of the viral replication in the early and late stages, as a radical scavenger, and as an anticancer agent against triple negative breast cancer (MDA-MB-231) and acute lymphoblastic leukemia (CEM) cells.

\section{Effect of compound 2a on the early stages of the HIV-1 life cycle}

The effect of compound 2a on the infectivity of VSV-G pseudotyped HIV-1 single-round infection viruses expressing LTRdriven luciferase (HIV-luc) was evaluated using the human $\mathrm{CD}^{+}{ }^{+} \mathrm{T}$ cell line SupT1. These cells were infected with HIV-luc in the presence of DMSO (vehicle control) or fullerene $2 \mathrm{a}(10 \mu \mathrm{M})$ and $24 \mathrm{~h}$ later the compound and the input virus were removed. After three days cellular luciferase and ATP levels were measured, and luciferase was normalized to ATP to adjust for cell viability and number. In these experiments, compound 2a

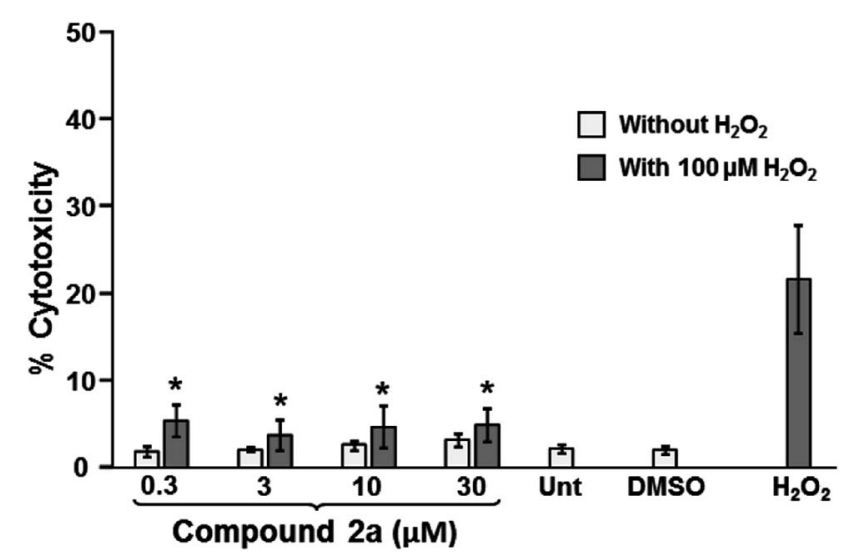

Fig. 2 Compound 2a significantly mitigates $\mathrm{H}_{2} \mathrm{O}_{2}$-induced oxidative stress in human neuroblastoma SH-SY5Y cells. Cells seeded in a 96 well plate were pretreated with a compound $2 \mathrm{a}$ concentration gradient $(\mu \mathrm{M})$ for $1 \mathrm{~h}$, followed by addition of $100 \mu \mathrm{M}$ of $\mathrm{H}_{2} \mathrm{O}_{2}$ and incubated for an additional $24 \mathrm{~h}$ (dark gray bars). A series of cell samples treated with just compound 2 a (light gray bars), without $\mathrm{H}_{2} \mathrm{O}_{2}$, were analyzed concomitantly. Additional controls were untreated cells (Unt), cells treated with DMSO (solvent control) and cells treated with $100 \mu \mathrm{M} \mathrm{H}_{2} \mathrm{O}_{2}$ alone (positive control for cytotoxicity). Each bar represents the average of eight replicas and error bars their corresponding standard deviation. The $P$ values were consistently $<0.00001$ $(*)$, when comparing the compound $2 \mathrm{a}$-pretreated cells with cells treated with $\mathrm{H}_{2} \mathrm{O}_{2}$ alone. only minimally affected HIV-1 infectivity (Fig. 1a). These results indicate that fullerene $\mathbf{2 a}$ did not affect the early stages of the HIV-1 life cycle required for HIV-driven luciferase expression including viral entry and uncoating, reverse transcription, integration of viral cDNA, and HIV-1 Tat-mediated gene expression. These results also demonstrated that these compounds were not toxic to SupT1 cells at $10 \mu \mathrm{M}$ concentration.

\section{Effect of compound 2a on the late stages of the HIV-1 life cycle}

To evaluate the effects of $\mathbf{2 a}$ in the late stages of viral development, we produced HIV-luc by plasmid transfection in HEK293T cells (obtained from Dr Eric Poeschla lab from Mayo Clinic) in the presence of DMSO, fullerene $2 \mathrm{a}(3 \mu \mathrm{M})$, or indinavir $^{33}(0.1 \mu \mathrm{M})$. The latter is a PR inhibitor known to potently inhibit HIV-1 maturation. Viruses were concentrated by ultracentrifugation through a sucrose cushion, normalized for p24 levels, and their infectivity evaluated in untreated SupT1 cells (Fig. 1b). As expected, indinavir resulted in 96\% inhibition at $0.1 \mu \mathrm{M}$, as compared to DMSO. On the other hand, compound 2a inhibited by $64 \%$ the infectivity at $3 \mu \mathrm{M}$ (Fig. $1 \mathrm{~b}$ ).

The plasmids used to generate retroviral vectors were described previously. ${ }^{31}$ HIV-1-derived vectors were produced using pHIV Luc and pMD.G. pHIV Luc was derived from pNL43.Luc.R-E- ${ }^{32}$ by introducing a deletion in the env open reading frame (Bright-Glow ${ }^{\mathrm{TM}}$ Luciferase Assay System, Promega).

\section{Compound 2a exhibits cytoprotective activity in human neuroblastoma cells undergoing oxidative stress}

A human SH-SY5Y cell line (ATCC) was selected to review the cytoprotective activity of compound $\mathbf{2 a}$; an established cell

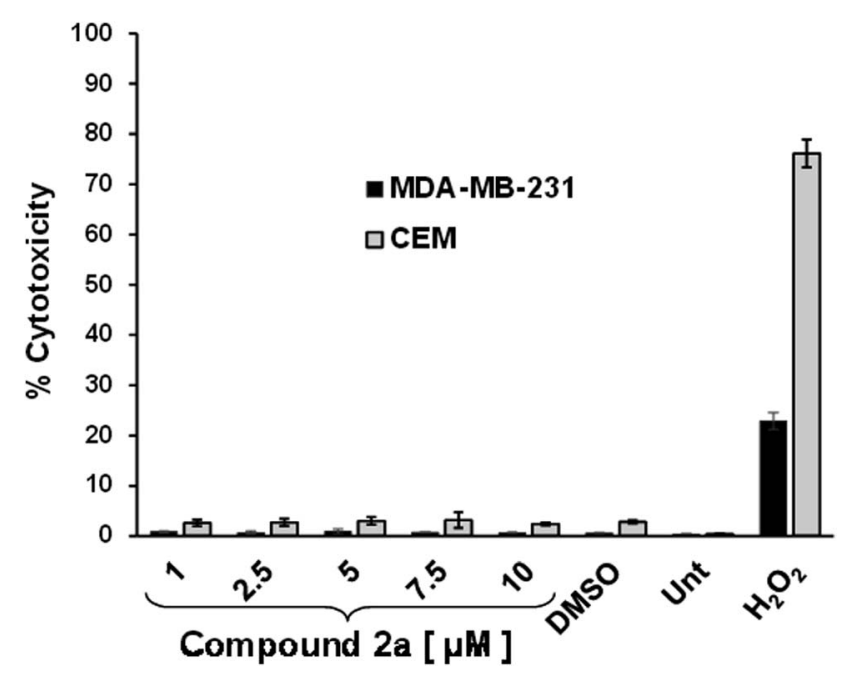

Fig. 3 Analysis of the cytotoxic properties of compound 2a against MDA-MB-231 and CEM human cancer cell lines. To examine the percentage of cytotoxicity ( $y$-axis) an IN Cell 2000 bioimager system (GE Healthcare) and differential nuclear staining assay were utilized. Cells were incubated for $48 \mathrm{~h}$ in the presence of various concentrations of compound $2 \mathrm{a}$ ( 1 to $10 \mu \mathrm{M})$. The following controls were included: as a positive control for cytotoxicity $\mathrm{H}_{2} \mathrm{O}_{2}(1 \mathrm{mM})$; as a solvent control, $0.1 \%$ v/v DMSO; and untreated cells (Unt). Results shown are the average and standard deviation of four replicates. 
model of dopaminergic neurons to study Parkinson's disease in vitro. ${ }^{34}$ The cell death percentages were quantified by using the DNS assay and examined via high throughput screening bioimager system (GE Healthcare). ${ }^{35,36}$ Cells pretreated $(1 \mathrm{~h})$ with $0.3,3,10$ and $30 \mu \mathrm{M}$ of compound $2 \mathrm{a}$ were subsequently exposed ( $24 \mathrm{~h}$ ) to $100 \mu \mathrm{M}$ of $\mathrm{H}_{2} \mathrm{O}_{2}$, to inflict the cellular oxidative stress and cell death. As expected, the $\mathrm{H}_{2} \mathrm{O}_{2}$-treated cells, without any pretreatment, exhibited the maximum value of cytotoxicity (21.71 $\pm 6.22 \%$; Fig. 2). All concentrations of compound $\mathbf{2 a}$ tested displayed a consistently significant reduction in cytotoxicity after adding $\mathrm{H}_{2} \mathrm{O}(100 \mu \mathrm{M} ; 24 \mathrm{~h})$ when compared with the cells treated with just $\mathrm{H}_{2} \mathrm{O}_{2}$ (Fig. 2). The cytotoxicity percentage values were $5.43 \pm 1.89,3.76 \pm 1.79,4.69$ \pm 2.41 and $4.92 \pm 1.9$ (average $\pm \mathrm{SD}$ ), when $0.3,3,10$ and $30 \mu \mathrm{M}$ of compound $2 \mathbf{a}$ were tested, respectively (Fig. 2); around $77 \%$ in reduction of cytotoxicity, which is considered highly significant $(P<0.00001)$. Moreover, compound $2 \mathrm{a}$ itself showed no cytotoxic activity at all concentrations reviewed after $25 \mathrm{~h}$ of cell exposure (around 4.7\%; light gray bars; Fig. 2). These cytotoxicity percentage values were very similar to DMSO and untreated negative control cells. These findings indicate that compound 2a alone is not toxic to cells under the conditions tested in this study. Therefore, even at nanomolar concentrations (300 nM), compound 2a possesses a strong antioxidant and

Table 1 Electrochemical and photophysical data of compounds 2a-h. $\mathrm{PC}_{61} \mathrm{BM}$ values were taken from the literature ${ }^{46 a}$

\begin{tabular}{llllll}
\hline Compound & $\begin{array}{l}\lambda_{\text {abs }} \\
(\mathrm{nm})\end{array}$ & $E_{\mathrm{g}}(\mathrm{eV})$ & $E_{\text {red }}^{\text {onset }}(\mathrm{V})$ & LUMO $(\mathrm{eV})$ & HOMO $(\mathrm{eV})$ \\
\hline $\mathbf{P C}_{\mathbf{6 1}} \mathbf{B M}$ & 718 & 1.73 & -0.90 & -3.90 & -5.63 \\
$\mathbf{2 a}$ & 716 & 1.73 & -1.09 & -3.93 & -5.66 \\
$\mathbf{2 b}$ & 718 & 1.73 & -1.08 & -3.94 & -5.67 \\
$\mathbf{2 c}$ & 718 & 1.73 & -1.09 & -3.93 & -5.66 \\
$\mathbf{2 d}$ & 714 & 1.74 & -1.13 & -3.89 & -5.63 \\
$\mathbf{2 e}$ & 720 & 1.72 & -1.07 & -3.95 & -5.67 \\
$\mathbf{2 f}$ & 716 & 1.73 & -1.02 & -4.00 & -5.73 \\
$\mathbf{2 g}$ & 718 & 1.73 & -1.10 & -3.92 & -5.65 \\
$\mathbf{2 h}$ & 718 & 1.73 & -1.09 & -3.93 & -5.66
\end{tabular}

${ }^{a}$ Values obtained using the following formula $E_{\mathrm{LUMO}}=-\left(E_{\text {red }}^{\text {onset } v s \mathrm{Fc}^{+} / \mathrm{Fc}}+4.8\right) \mathrm{eV} .^{45}$ neuroprotective activity on human dopaminergic neurons $\mathrm{SH}$ SY5Y cells, experiencing $\mathrm{H}_{2} \mathrm{O}_{2}$-induced oxidative stress, probably acting as an effective free radical scavenger reagent.

\section{Effect of compound 2a as an anticancer agent}

The potential anticancer activity of compound 2a was examined in two human cancer cell lines; MDA-MB-231 triple negative breast cancer and CEM acute lymphoblastic leukemia cells (both from ATCC, Manassas, VA) by a differential nuclear staining assay ${ }^{34-36}$ (see ESI $\uparrow$ for details). Both cell lines exhibited insignificant amounts of cytotoxicity when exposed to compound 2a in a gradient of concentrations ranging from 1 to $10 \mu \mathrm{M}$ for $48 \mathrm{~h}$ (Fig. 3). As shown in Fig. 3 the cytotoxicity values observed for compound 2a-treated cells lines consistently resembled the values of the untreated (Unt) and DMSO vehicle controls, suggesting that compound 2a has no cytotoxic activity against triple negative breast cancer and acute lymphoblastic leukemia cells. $\mathrm{H}_{2} \mathrm{O}_{2}(1 \mathrm{mM})$ was included as a positive control of death, and as expected, the highest cytotoxic values were observed; $22.9 \%$ and $76.1 \%$ for MDA-MB-231 and CEM cells respectively. These last results indicate that MDA-MB-231 cells were more resistant to the $\mathrm{H} 2 \mathrm{O} 2(1 \mathrm{mM})$, as compared with CEM cells.

\section{Photovoltaic properties of fullerocurcuminoids $2 \mathrm{a}-\mathrm{h}$}

Due to the extended conjugation of the CCM/CCMoid backbones, these compounds have been extensively studied as lightharvesting materials in bulk heterojunction (BHJ) and dyesensitized (DS) solar cells,,$^{37-40}$ and PCE values up to $4.1 \%{ }^{37}$ and $5.8 \%^{40}$ have been obtained, respectively. Since fullerocurcuminoids $\mathbf{2 a}-\mathbf{h}$ have not been synthetized before they have not been tested in PSCs as the electron transporting layers (ETLs) nor as the hole transporting layers (HTLs).

The optical properties of the fullerocurcuminoid derivatives $\mathbf{2 a - k}$ were investigated by means of UV/Vis spectroscopy. As seen in Fig. S33, $\uparrow \mathbf{2 a - k}$ exhibit absorption bands below $400 \mathrm{~nm}$ arising from both functionalities, $\mathrm{C}_{60}$ and the aromatic endings of the CCMoids. Between 400-450 $\mathrm{nm}$ the bands observed for the majority of the compounds correspond to the skeleton of the CCMoid moieties and in the case of $\mathbf{2 e}$, the absorption band at the highest wavelength is linked to the ferrocene groups. ${ }^{41-43}$ a)

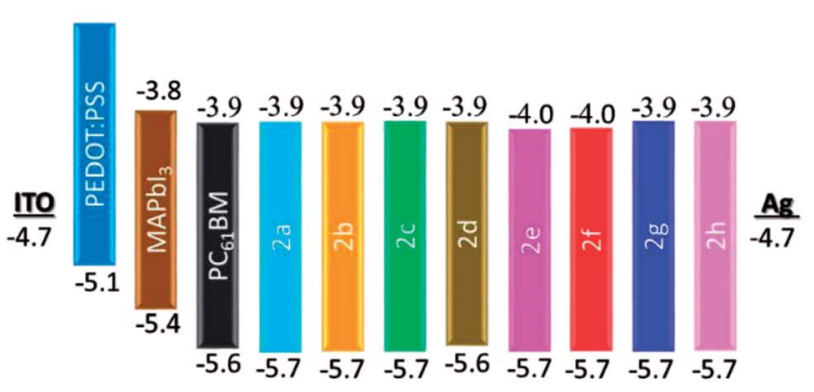

b)

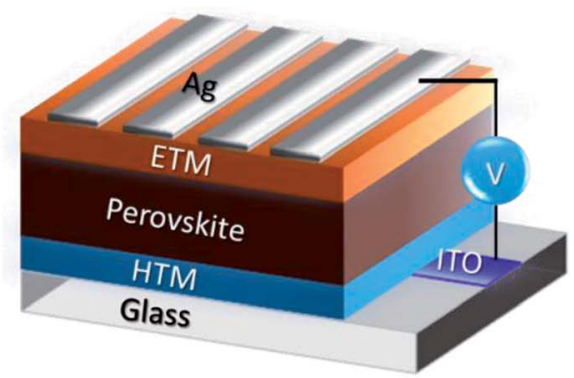

Fig. 4 (a) Schematic illustration of the estimated HOMO and LUMO energy levels, calculated from CV and UV-vis, (b) PSCs' cell architectures. 
a)

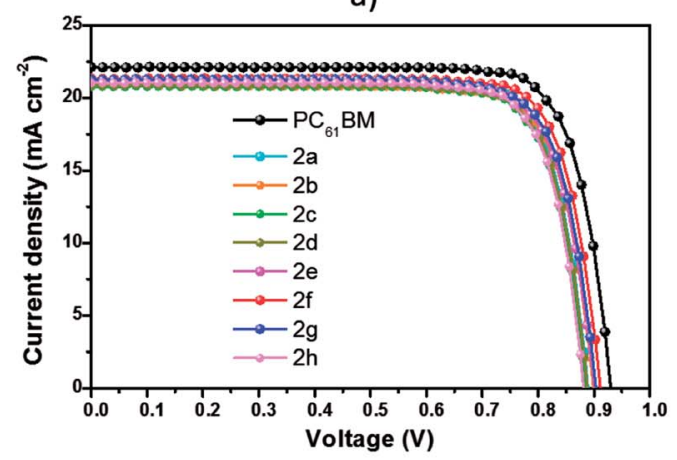

c)

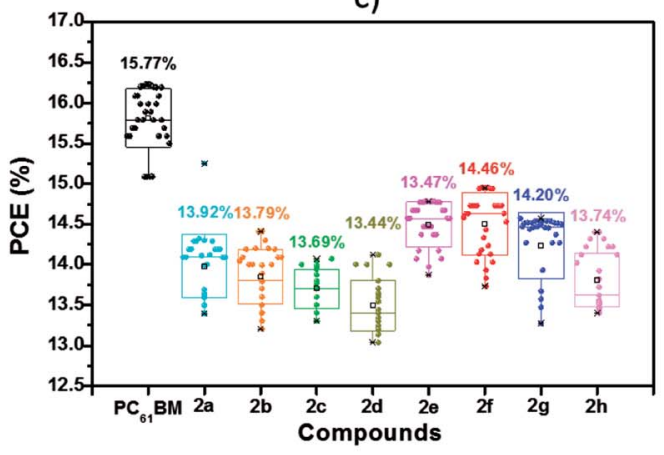

b)

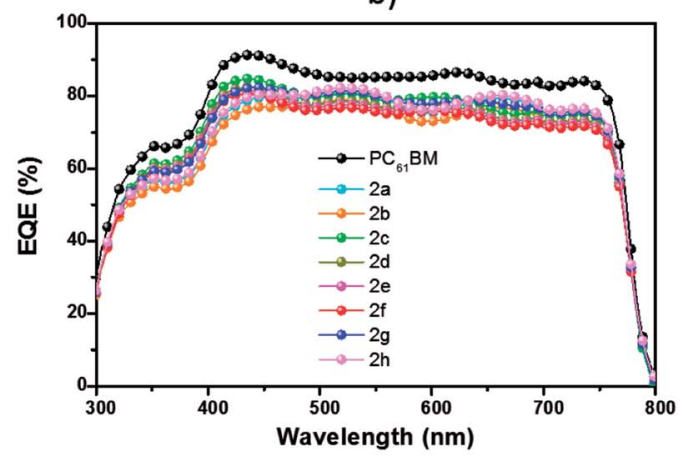

d)

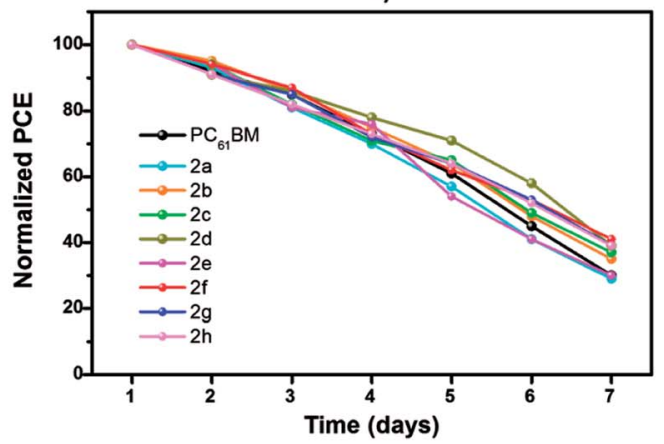

Fig. 5 (a) J-V curves under 1 sun illumination $\left(100 \mathrm{~mW} \mathrm{~cm}^{-2}\right)$ in forward voltage scans. (b) EQE spectra for the PSCs fabricated using compounds $2 \mathrm{a}-\mathrm{h}$ and $\mathrm{PC}_{61} \mathrm{BM}$ as the ETMs. (c) The PCE histograms measured for 32 independent cells. (d) Normalized PCEs of PSCs measured as a function of time in $\sim 20 \%$ humidity at room temperature for seven days.

The electrochemical properties of $\mathbf{2 a}-\mathbf{h}$ and $\mathbf{P C}_{\mathbf{6 1}} \mathbf{B M}$ were determined by cyclic voltammetry (CV) in $o$-DCB as described in the EIS. As shown in Fig. S34, $\dagger$ compounds 2a-h exhibit reversible and quasi-reversible cathodic electrochemical behavior between -1.0 and $-1.3 \mathrm{~V}$, whereas more negative potentials lead to irreversible retro-cycloadditions. ${ }^{44}$ In particular compounds $\mathbf{2 d}, \mathbf{2 e}$ and $\mathbf{2 f}$ showed chemical reversibility for the first reduction step at a scan rate of $100 \mathrm{mV} \mathrm{s}^{-1}$, followed by chemical and electrochemically irreversible waves. The highest occupied molecular orbital/lowest unoccupied molecular orbital (HOMO/LUMO) values were estimated from the UV and CV measurements. ${ }^{45}$ The optical properties of compounds $2 \mathbf{a}-\mathbf{h}$ are summarized in Table 1.
Compounds 2a-h exhibit similar HOMO/LUMO values to those of $\mathbf{P C}_{\mathbf{6 1}} \mathbf{B M}$, thus they are a good match for the conduction and valence bands of the perovskite, respectively, ${ }^{47}$ and should provide efficient electron collection and hole blocking ability. The schematic representation of the work function of the PSCs is illustrated in Fig. 4a.

We studied the electron transporting ability of compounds 2a-h in PSCs with the configuration of ITO/PEDOT:PSS/ perovskite/ETM/Ag (Fig. 4b), and compared them to $\mathbf{P C}_{61} \mathbf{B M}$. The cells were fully characterized using SEM, XRD, and photovoltaic measurements (Fig. S35 and S36, $\dagger$ respectively). As shown in Fig. 5a, devices based on 2a-h show PCEs ranging from $14.04-14.95 \%$. The main photovoltaic characteristics are

Table 2 Summary of the main photovoltaic performance of PSCs using $2 \mathrm{a}-\mathrm{h}$ as the ETMs ${ }^{a}$

\begin{tabular}{|c|c|c|c|c|c|}
\hline Compound & Calculated $J_{\mathrm{sc}}\left(\mathrm{mA} \mathrm{cm}^{-2}\right)$ & $J_{\mathrm{sc}}\left(\mathrm{mA} \mathrm{cm}{ }^{-2}\right)$ & $V_{\mathrm{oc}}(\mathrm{V})$ & $\mathrm{FF}(\%)$ & PCE (\%) \\
\hline $\mathrm{PC}_{61} \mathrm{BM}$ & 21.87 & 22.10 & 0.93 & 0.79 & $15.73 \pm 0.46(16.23)$ \\
\hline $2 \mathbf{a}$ & 21.02 & 21.14 & 0.89 & 0.76 & $13.92 \pm 0.38(14.30)$ \\
\hline $2 c$ & 20.35 & 20.77 & 0.89 & 0.76 & $13.69 \pm 0.35(14.04)$ \\
\hline $2 d$ & 20.63 & 20.87 & 0.89 & 0.76 & $13.44 \pm 0.68(14.12)$ \\
\hline $2 e$ & 21.27 & 21.33 & 0.90 & 0.77 & $13.47 \pm 1.31(14.78)$ \\
\hline $2 \mathrm{~h}$ & 20.86 & 21.02 & 0.89 & 0.77 & $13.74 \pm 0.66(14.40)$ \\
\hline
\end{tabular}

${ }^{a}$ Calculated $J_{\mathrm{sc}}$ from EQE measurements, values in parentheses are the highest PCEs. 
summarized in Table 2. These PCEs, although lower than for the control $\mathbf{P C}_{\mathbf{6 1}} \mathbf{B M}(16.23 \%)$, are significant and promising. The integrated photocurrent densities based on EQE measurements (Fig. 5b) are consistent with those obtained from $J-V$ measurements (Table 2). Devices prepared with all the fullerene derivatives including $\mathbf{P C}_{\mathbf{6 1}} \mathbf{B M}$ exhibit a high photo response within the entire visible range. Device performance reproducibility was calculated from the PCE distributions measured for 32 independent cells (Fig. 5c). The long term-device stabilities for PSCs were conducted under $\sim 20 \%$ humidity at room temperature without encapsulation for seven days. Fig. 5d, shows the normalized PCEs vs. time. After seven days of periodic measurements, devices based on $\mathbf{2 a}-\mathbf{h}$ and $\mathbf{P C}_{\mathbf{6 1}} \mathbf{B M}$ lost $60 \%$ of their initial PCE. No significant differences were observed for devices prepared either with compounds $2 \mathbf{a}-\mathbf{h}$ or $\mathbf{P C}_{\mathbf{6 1}} \mathbf{B M}$. These encouraging results will be studied in more detail in the future to fully understand the roles of aggregation as well as that of interface interactions between the $\mathrm{C}_{60^{-}}$ CCMoids and the perovskite films.

\section{Conclusions}

In this work, we describe for the first time the conjugation of curcumin-like compounds to fullerene $\mathrm{C}_{60}$ through a Bingel type reaction to obtain new fullerocurcuminoid derivatives. Fullerocurcuminoid 2a was soluble in DMSO and was tested as an anti-HIV-1 agent, as a radical scavenger, and as an anticancer agent. When studying the late stages of the HIV viral cycle, compound $2 \mathrm{a}$ inhibits $64 \%$ of the HIV-1 viral infection at $3 \mu \mathrm{M}$ and it also prevents radical damage at this concentration. No anticancer activity was detected in our assays. These results are consistent with those for curcuminoid, which exhibits low toxicity and no anticancer activity toward several cell lines. In addition, fullerocurcuminoids $\mathbf{2 a - h}$ were soluble in chlorobenzene, and exhibit HOMO/LUMO energy levels that match those of perovskites, therefore, when they were tested in PSCs as the ETMs, PCEs in the range of 14.04-14.95\%, were obtained. A value of $16.23 \%$ was obtained for $\mathbf{P C}_{61} \mathbf{B M}$-based devices. Further studies are needed to understand the nature of the photovoltaic activity as well as to improve the observed performances.

\section{Conflicts of interest}

There are no conflicts to declare.

\section{Acknowledgements}

The authors thank the US National Science Foundation (NSF) for the generous support of this work under the NSF-PREM program DMR 1205302 and CHE-1801317 (to L. E.). The Robert A. Welch Foundation is also gratefully acknowledged for an endowed chair to L. E. (Grant AH-0033). MS acknowledges support through the FONDECYT Grant Number 1161775, 3170509. AEB thanks Conicyt PFCHA 21140734 for a PhD scholarship. The work of N. A.-A. has been supported by the Spanish Government by the project MAT2016-77852-C2-1-R and acknowledge the "Severo Ochoa" Program for Centres of Excellence in R\&D (SEV-2015-0496). N. A.-A. and W. Q. thanks to the Generalitat de Catalunya, FI-DGR grant 2014. R. D.-T. thanks to the Fundació Montcelimar. A. E. B., M. S and N. A.A. thank to the CSIC (project iCOOP20162). ML thanks the National Institute of General Medical Sciences (NIGMS) Grant Number 5 SC1 AI098238-02 and the National Institutes of Health (NIH). The Cytometry, Screening and Imaging Core Facility-BBRC-UTEP that was used in this work was supported by the National Institute on Minority Health and Health Disparities (NIMHD) through a Research Centers for Minority Institutions (RCMI) grant [5G12MD007592] a component of NIH. We also thank Dr Narayan for helping us with the antiradical experiments.

\section{References}

1 H. W. Kroto, J. R. Heath, S. C. O'Brien, R. F. Curl and R. E. Smalley, Nature, 1985, 318, 162-163.

2 A. Montellano Lopez, A. Mateo-Alonso and M. Prato, in Fullerenes: Principles and Applications (2), The Royal Society of Chemistry, 2012, pp. 389-413.

3 E. Castro, A. H. Garcia, G. Zavala and L. Echegoyen, J. Mater. Chem. B, 2017, 5, 6523-6535.

4 E. Castro, J. Murillo, O. Fernandez-Delgado and L. Echegoyen, J. Mater. Chem. C, 2018, 6, 2635-2651.

5 S. H. Friedman, D. L. DeCamp, R. P. Sijbesma, G. Srdanov, F. Wudl and G. L. Kenyon, J. Am. Chem. Soc., 1993, 115, 6506-6509.

6 R. Sijbesma, G. Srdanov, F. Wudl, J. A. Castoro, C. Wilkins, S. H. Friedman, D. L. DeCamp and G. L. Kenyon, J. Am. Chem. Soc., 1993, 115, 6510-6512.

7 E. Castro, Z. S. Martinez, C. S. Seong, A. Cabrera-Espinoza, M. Ruiz, G. Hernandez, A. F. Valdez, M. Llano and L. A. Echegoyen, J. Med. Chem., 2016, 59, 10963-10973.

8 Z. S. Martinez, E. Castro, C. S. Seong, M. R. Ceron, L. Echegoyen and M. Llano, Antimicrob. Agents Chemother., 2016, 60, 5731-5741.

9 N. Gharbi, M. Pressac, M. Hadchouel, H. Szwarc, S. R. Wilson and F. Moussa, Nano Lett., 2005, 5, 2578-2585.

10 T. Kop, M. Bjelaković and D. Milić, Tetrahedron, 2015, 71, 4801-4809.

11 T. Baati, F. Bourasset, N. Gharbi, L. Njim, M. Abderrabba, A. Kerkeni, H. Szwarc and F. Moussa, Biomaterials, 2012, 33, 4936-4946.

12 N. Higashi, T. Shosu, T. Koga, M. Niwa and T. Tanigawa, J. Colloid Interface Sci., 2006, 298, 118-123.

13 G. V. Andrievsky, V. I. Bruskov, A. A. Tykhomyrov and S. V. Gudkov, Free Radical Biol. Med., 2009, 47, 786-793.

14 R. Angelique, Y. W. Yan, F. J. Marcel and H. Barbara, Exp. Dermatol., 2017, 26, 220-224.

15 N. S. Allen, E. B. Zeynalov, K. Taylor and P. Birkett, Polym. Degrad. Stab., 2009, 94, 1932-1940.

16 R. Czochara, J. Kusio and G. Litwinienko, RSC Adv., 2017, 7, 44021-44025.

17 S. Hewlings and D. Kalman, Foods, 2017, 6, 92. 
18 P. Neerati, Y. A. Sudhakar and J. R. Kanwar, J. Cancer Sci. Ther., 2013, 5, 313-319.

19 M. Asouri, R. Ataee, A. A. Ahmadi, A. Amini and M. R. Moshaei, Asian J. Chem., 2013, 25, 7593-7595.

20 J. K. Jackson, T. Higo, W. L. Hunter and H. M. Burt, Inflammation Res., 2006, 55, 168-175.

21 G. M. Cole, F. Yang, G. P. Lim, J. L. Cummings, D. L. Masterman and S. A. Frautschy, Curr. Med. Chem.: Immunol., Endocr. Metab. Agents, 2003, 3, 15-25.

22 H. Nishikawa, J. Tsutsumi and S. Kitani, J. Funct. Foods, 2013, 5, 763-772.

23 B. B. Aggarwal and K. B. Harikumar, Int. J. Biochem. Cell Biol., 2009, 41, 40-59.

24 A. Goel, A. B. Kunnumakkara and B. B. Aggarwal, Biochem. Pharmacol., 2008, 75, 787-809.

25 K. M. Nelson, J. L. Dahlin, J. Bisson, J. Graham, G. F. Pauli and M. A. Walters, J. Med. Chem., 2017, 60, 1620-1637.

26 M. Bernabé-Pineda, M. a. T. Ramírez-Silva, M. RomeroRomo, E. González-Vergara and A. Rojas-Hernández, Spectrochim. Acta, Part A, 2004, 60, 1091-1097.

27 H. Itokawa, Q. Shi, T. Akiyama, S. L. Morris-Natschke and K.-H. Lee, Chin. Med., 2008, 3, 11.

28 E. V. Rao and P. Sudheer, Indian J. Pharm. Sci., 2011, 73, 262270.

29 A. Amalraj, A. Pius, S. Gopi and S. Gopi, J. Tradit. Complement. Med., 2017, 7, 205-233.

30 C. Bingel, Chem. Ber., 1993, 126, 1957-1959.

31 M. Llano, D. T. Saenz, A. Meehan, P. Wongthida, M. Peretz, W. H. Walker, W. Teo and E. M. Poeschla, Science, 2006, 314, 461-464.

32 J. He, S. Choe, R. Walker, P. Di Marzio, D. O. Morgan and N. R. Landau, J. Virol., 1995, 69, 6705-6711.

33 D. Leung, G. Abbenante and D. P. Fairlie, J. Med. Chem., 2000, 43, 305-341.
34 P. Kabiraj, J. E. Marin, A. Varela-Ramirez and M. Narayan, ACS Chem. Neurosci., 2016, 7, 1519-1530.

35 C. Lema, A. Varela-Ramirez and R. J. Aguilera, Curr. Cell. Biochem., 2011, 1, 1-14.

36 E. Robles-Escajeda, U. Das, N. M. Ortega, K. Parra, G. Francia, J. R. Dimmock, A. Varela-Ramirez and R. J. Aguilera, Cell. Oncol., 2016, 39, 265-277.

37 F. Archet, D. Yao, S. Chambon, M. Abbas, A. D’Aléo, G. Canard, M. Ponce-Vargas, E. Zaborova, B. Le Guennic, G. Wantz and F. Fages, ACS Energy Lett., 2017, 2, 1303-1307.

38 D. Sinha, D. De and A. Ayaz, Spectrochim. Acta, Part A, 2018, 193, 467-474.

39 M. Tsuchikawa, A. Takao, T. Funaki, H. Sugihara and K. Ono, RSC Adv., 2017, 7, 36612-36616.

40 H. Ozawa, H. Kawaguchi, Y. Okuyama and H. Arakawa, Ambio, 2012, 41, 149-150.

41 F. Langa and J. F. Nierengarten, Fullerenes: Principles and Applications, RSC, Cambridge, United Kingdom, 2011.

42 J. G. Domínguez-Chávez, E. Cruz-Chávez, I. Moggio, E. AriasMarín, T. Klimova, I. Lijanova and M. Martínez-García, Fullerenes, Nanotubes, Carbon Nanostruct., 2012, 20, 249-265.

43 M. H. Ucisik, S. Küpcü, B. Schuster and U. B. Sleytr, J. Nanobiotechnol., 2013, 11, 37.

44 G. L. Closs, P. Gautam, D. Zhang, P. J. Krusic, S. A. Hill and E. Wasserman, J. Phys. Chem., 1992, 96, 5228-5231.

45 Q. Sun, H. Wang, C. Yang and Y. Li, J. Mater. Chem., 2003, 13, 800-806.

46 C. Tian, E. Castro, G. Betancourt-Solis, Z.-A. Nan, O. Fernandez-Delgado, S. Jankuru and L. Echegoyen, New J. Chem., 2018, 42, 2896-2902.

47 P. Schulz, E. Edri, S. Kirmayer, G. Hodes, D. Cahen and A. Kahn, Energy Environ. Sci., 2014, 7, 1377-1381. 